\title{
DISCUSIÓN DE ALGUNAS TEORÍAS RECIENTES SOBRE LA NOCIÓN DE ORDEN JURÍDICO
}

\section{Tesis de Norberto Bobbio}

En su Teoria dell'ordinamento giuridico, editada por Giappichelli en 1960 dentro de la serie Corsi Universitari, Norberto Bobbio observa con razón que si bien existen numerosos estudios monográficos sobre la naturaleza y estructura de la norma de derecho, todavía no contamos con un tratado completo y orgánico sobre los múltiples problemas que plantea la existencia de un orden jurídico." "Los problemas generales del derecho han sido tradicionalmente discutidos desde el punto de vista de la norma, considerada como un todo que existe por sí, más bien que desde el punto de vista de esa norma como parte de un todo más amplio que la comprende." 2 Para confirmar este aserto, prosigue Bobbio, bastaría con pasar revista a las obras más importantes que han visto la luz en los últimos siglos, desde el famoso tratado De legibus ac Deo legislatore, de Francisco Suárez (1612), hasta los más recientes de Binding y Thon. ${ }^{3}$ Es verdad que en dichos trabajos se alude a ciertos problemas relacionados con el orden jurídico; pero éstos nunca son objeto de una consideración especial. Los autores de aquellos libros "veían el árbol, mas no el bosque".

Los primeros en sostener la autonomía del concepto de orden fueron, según Bobbio, los creadores de la teoría de la institución, especialmente Santi Romano. ${ }^{5}$ La mencionada teoría ha puesto en claro que "sólo se puede hablar de derecho allí donde hay un conjunto de normas que integran un orden, lo que revela que aquél no es norma, sino conjunto de normas coordinadas entre sí o, en otras palabras, que la norma de derecho no existe sola, sino ligada a otras con las que forma un sistema normativo. ${ }^{6}$

1 Traduzco "ordinamento giuridico" por "orden jurídico", porque Bobbio usa la citada expresión en el mismo sentido en que en francés se habla de ordre juridique; en alemán, de Rechtsordnung; en inglés, de legal order y, en español, de orden jurídico. pág. 4.

2 Bobbio, Teoria dell'ordinamento giuridico, G. Giappichelli Editore, Torino, 1960,

${ }^{3}$ Se refiere a Rechtsnorm und subjektives Recht (Norma juridica y derecho subjetivo), Weimar, Hermann Böhlau, 1878, de August Thon, y Die Normen und ihre Uebertretung, (Las normas '; su violación), 1872 y 1877, de Karl Binding.

4 Bobbio, Teoria dell'ordinamento giuridico, pág. 5.

5 Cfr. Santi Romano, L'ordinamento giuridico, Sansoni, Firenze, II Edizione, 1946, Ristampa della II Edizione, 1951.

6 Bobbio, Teoria dell'ordinamento giuridico, pág. 5. 
Un tratamiento autónomo de la cuestión se encuentra ya en Kelsen. Bobbio recuerda la General Theory of Law and State, de 1945, ${ }^{7}$ cuyas dos grandes partes llevan, respectivamente, los títulos de Nomostatics y Nomodynamics. La primera, como es sabido, discute los problemas que plantea la norma jurídica, en tanto que la segunda versa sobre los que atañen al derecho como orden.

Antes de redactar su Teoria dell'ordinamento el profesor italiano dedicó otro libro al estudio de las normas, publicado también por Giappichelli. ${ }^{8}$ En dicho trabajo llega a la conclusión de que no se puede definir el derecho cuando se parte de una teoría de la norma, aisladamente considerada. Para obtener un resultado satisfactorio es indispensable ampliar el horizonte de la pesquisa y establecer de qué modo los preceptos jurídicos obtienen eficacia dentro de una organización, asaz compleja, que determina la naturaleza y alcance de sus sanciones $\mathrm{e}$ indica cómo deben éstas ser aplicadas, y a quién incumbe tal tarea.

Después de referirse, en actitud crítica, a los ensayos encaminados a definir el derecho de acuerdo con el contenido de sus normas, con el fin de las mismas, con el sujeto que las formula, con los valores o ideales que pretenden realizar y con la índole de las obligaciones que imponen, ${ }^{9}$ Bobbio concluye que el único criterio que permite establecer con precisión los ámbitos del derecho, la moral y los convencionalismos sociales y, consecuentemente, definirlos con rigor, es el que consiste en atender al modo y manera en que las sanciones de esos órdenes responden a la violación de sus preceptos.

En el caso de la moral las sanciones son puramente internas. Por "sanción" entienden los moralistas "una consecuencia desagradable del acto violatorio, cuyo fin es prevenir la violación o, si ésta se ha consumado, eliminar sus efectos nocivos". ${ }^{10} \mathrm{La}$ única consecuencia desagradable de la desobediencia a una norma moral es "el sentimiento de culpa, estado de desazón, de intranquilidad, a veces de angustia, que en el lenguaje de la ética recibe el nombre de 'remordimiento' o "arrepentimiento" ". La moral "obliga en conciencia". Con ello quiere significarse que de su violación respondo ante mi fuero interno, por lo cual, si infrinjo sus prescripciones, mi propia conciencia es la única instancia que puede caśtigarme. Las sanciones internas - observa Bobbio- tienen el defecto de ser poco eficaces. En realidad sólo actúan en el caso de aquellos que pueden experimentar satisfacciones o insatisfacciones íntimas, es decir, en el de quienes, por regla general, acatan los imperativos morales en forma espontánea. "La

7 Hans Kelsen, General Theory of Law and State, Harvard University Press, Cambridge, Massachusetts, 1945. La Teoria General del Derecho y del Estado, de Kelsen, fue traducida al castellano por el autor de este artículo, y publicada por la Universidad Nacional Autónoma de México. La segunda edición es de 1958. 1958.

${ }^{8}$ Norberto Bobbio, Teoria della norma giuridica. G. Giappichelli Editore, Torino,

9 Bobbio, Teoria della norma giuridica, cap. V, 37-47.

10 Ibíd., pág. 190.

11 Idem. 
sanción interna considérase socialmente tan poco efectiva, que las normas morales son a menudo reforzadas con sanciones de orden religioso, que ya no tienen carácter interno, sino externo." Pues "no hay ningún legislador que para lograr que sus normas sean respetadas confíe exclusivamente en la operatividad de la sanción interior". 12

A diferencia de las de orden moral, las de los convencionalismos sociales y el derecho son de índole externa. Reciben este calificativo las que provienen de sujetos distintos del obligado, ya sea que se les considere aisladamente o en conjunto. La sanción externa "es característica de todas las normas de la costumbre, de la urbanidad $y$, en general, de la vida colectiva que sirven al propósito de hacer más llevadera o menos difícil la convivencia. Estas normas nacen, generalmente, en forma de hábitos de un grupo social que responde a la violación con diversos comportamientos constitutivos de las sanciones". ${ }^{13}$

Las de carácter social tienen también un defecto, pero no es la falta de eficacia, sino la de proporción entre el acto violatorio y la respuesta del grupo. Como su imposición se atribuye a este último, impersonalmente considerado, o a miembros del mismo no definidos personalmente, nunca son impuestas de acuerdo con reglas precisas. De aquí "la incertidumbre de sus resultados, la inconstancia de su aplicación y la falta de medida entre la violación y la respuesta". ${ }^{4}$

Para evitar los inconvenientes de la sanción interna y los de la externa no institucionalizada, el grupo social institucionaliza las sanciones, es decir, amén de regular el comportamiento de los coasociados, regula igualmente las conductas violatorias. El orden que responde a la infracción de sus preceptos con sanciones institucionalizadas es, precisamente, el jurídico.

Cuando se habla de institucionalización de las sanciones, con ello -escribe Bobbio- quieren expresarse tres cosas, que no se implican en todo caso. "En primer lugar, que a cada norma primaria se halla ligada (con ciertas excepciones que él mismo señala) otra secundaria impositiva de la sanción. En segundo término, que las sancionadoras determinan siempre, dentro de ciertos límites, la medida del castigo. Y, por último, que la aplicación de éste y, en caso necesario, de las medidas coactivas, corresponde a órganos especiales, cuya actividad se encuentra normativamente regulada. La primera de las tres limitaciones asegura la certeza de la respuesta; la segunda es garantía de proporcionalidad y, la tercera, de imparcialidad de los órganos aplicadores." 15

La norma jurídica puede, pues, definirse como aquella cuya eficacia está garantizada por sanciones externas de tipo institucional. ${ }^{16} \mathrm{La}$ definición precedente confirma la tesis de que el teórico general del derecho debe abandonar el

12 Teoria della norma giuridica, pág. 193.

13 Idem.

14 Idem., pág. 196.

15 Ibíd., pág. 199.

16 Idem. 
examen de la norma aislada para dirigir su atención al ordenamiento jurídico en globo. Si sólo es jurídica la sanción institucionalizada, ello indica que, para que haya derecho, es indispensable que detrás de las normas exista una organización encargada de aplicar y, si es preciso, imponer los preceptos del sistemá. En otras palabras: "Lo que solemos llamar derecho es un carácter de ciertos ordenamientos normativos, más que de ciertas normas." 17 Pero entonces, el problema definitorio se convierte en problema de definición de un orden normativo, y no de cierta especie de normas. Para caracterizar a éstas basta con decir que son jurídicas las que forman parte de un orden jurídico, con lo que la cuestión que estriba en determinar qué es lo jurídico se desplaza de la norma al orden que la comprende. Por ello, aun cuando puede haber disposiciones legales no sancionadas - ya que es imposible sancionarlas todas- no puede, en cambio, existir un orden jurídico desprovisto de aparatos de coerción.

"Mientras que para la teoría tradicional tal orden se compone de normas, para la nueva perspectiva normas jurídicas son las que forman parte de un orden jurídico. En otros términos: no hay órdenes jurídicos porque haya normas jurídicas distintas de otras no jurídicas; sino que hay normas jurídicas porque hay órdenes jurídicos distintos de otros no jurídicos. El término 'derecho', en la más común acepción de derecho objetivo, indica una especie de sistema normativo, no una especie de norma." 18

Obtenida esta conclusión, Bobbio se pregunta qué problemas plantea el estudio de aquellos órdenes, y observa que tales problemas necesariamente derivan de las relaciones que guardan entre sí las normas que los componen.

En primer lugar se trata de saber si los órdenes jurídicos constituyen una unidad y, de qué modo la constituyen. La cuestión básica, en relación con el punto, es la de la jerarquia de las normas.

Seguidamente hay que inquirir si el orden jurídico, además de una unidad, constituye un sistema. Y el problema central, en el caso, es el de las antinomias.

Una tercera cuestión estriba en saber "si todo orden jurídico, unitario y tendencial (si no efectivamente) sistemático, pretende también ser completo"." Y el meollo de la cuestión es ahora el problema de las lagunas del derecho.

Pero como entre los hombres no sólo existe un orden, sino varios y de diverso tipo, resulta indispensable discutir -y éste es el último de los grandes tópicos - si entre aquellos órdenes hay relaciones, y de qué naturaleza.

De las respuestas qué el jurista italiano ofrece sólo queremos examinar, en este artículo, la primera, es decir, la relativa al problema de la unidad.

Nuestro autor enfoca la cuestión a la manera kelseniana y, consecuentemente, su punto de partida en la Stufentheorie de los juristas de la Escuela de Viena. Después de explicar la estructura escalonada de los órdenes jurídicos y hacer

17 Teoria dell'ordinamento giuridico, pág. 15.

18 Ibíd., pág. 18.

19 lbid., pág. 23. 
referencia a la teoria de la norma básica, se detiene en el concepto de constitución y afirma que "si hay normas constitucionales, debe necesariamente existir el poder de que tales normas derivan", esto es, el llamado "constituyente". ${ }^{20} \mathrm{Si}$ tal poder es el último, tendremos que presuponer la existencia de la norma que le atribuye la facultad de producir preceptos de derecho. Dicha norma, indispensable para fundar el sistema normativo, tiene carácter implícito, pero podría explicitarse de esta guisa: "La colectividad está obligada a obedecer las normas emanadas del poder constituyente." 2i

La norma fundamental - prosigue Bobbio- no es sólo indispensable para establecer la unidad de los órdenes jurídicos, sino para dar un fundamento de validez a las normas que los integran.

Como la fundamental ordena obedecer las emanadas del poder originario, y éste no es sino el conjunto de las fuerzas políticas que en un determinado momento histórico han logrado instaurar un orden jurídico, a fin de cuentas parece que "hacer depender todo el sistema del poder originario, significa reducir el derecho a la fuerza".2

Cuando aquella norma estatuye que se debe obedecer al poder originario, lo que realmente exige de nosotros es que respetemos el sistema normativo que encuentra en ella la razón última de su fuerza obligatoria. No puede negarse, sin embargo, que detrás de tal sistema están siempre los gobernantes, y que éstos tienen fuerza suficiente para hacer cumplir sus mandatos. La fuerza es, pues, instrumento necesario del poder, pero con ello no queda dicho que sea también su fundamento. En otros términos: es necesaria "para ejercitarlo, no para justificarlo". ${ }^{23}$

Si se reconoce que el derecho descansa en el poder y por poder se entiende el coercitivo, es decir, el de hacer respetar, incluso recurriendo a medios violentos, las normas en vigor, lo que en último análisis se declara es que, siendo el derecho un conjunto de reglas de eficacia reforzada, ${ }^{24}$ resulta impensable un orden jurídico detrás del cual no exista una organización de tipo coactivo. Pero "hacer del poder el fundamento último de un orden positivo no significa reducir el derecho a la fuerza, sino simplemente reconocer que ésta es necesaria para la realización de aquél. $\mathbf{Y}$ ello equivale a remachar el concepto del derecho como orden de eficacia reforzada". ${ }^{25}$

Pero si la fuerza es indispensable para la realización del derecho, sólo será derecho el que pueda hacerse valer por medio de ella. En otras palabras: " $U n$ orden jurídico sólo existe en tanto en cuanto es eficaz." 26

20 Teoria della norma giuridica, pág. 52.

21 Ibidd., pág. 53.

22 Ibid., pág. 61 .

23 Ibid., pág. 63

24 Ibíd., pág. 200.

25 Ibid., pág. 62.

26 Ibíd., pág. 63. 
Pensamos que la Teoria dell'ordinamento tiene el gran mérito de demostrar, frente a los enfoques tradicionales, la autonomía e importancia de los problemas relativos al orden jurídico. No basta con decir que las normas del derecho constituyen un orden, sino que es indispensable hacer un análisis de esta noción, definirla con rigor y descubrir la estructura del objeto a que se encuentra referida. Las conclusiones a que Bobbio llega en su Teoria della norma giuridica $\mathrm{y}$, especialmente, el aserto de que para diferenciar el derecho de otros órdenes reguladores de la conducta hay que tomar como punto de arranque no el estudio de las normas, sino el del orden que las abarca, resultan plenamente confirmados en la obra de 1960. De la fecundidad de este planteamiento son buena prueba los desarrollos que dicha obra contiene, tanto los relativos a la noción general de orden jurídico, como los que el autor ofrece al discutir problemas mucho menos generales, como el de las antinomias ${ }^{27} \mathrm{y}$ el de las lagunas del derecho. ${ }^{28}$

Lo más valioso de los dos libros que he venido comentando -y que, como el mismo Bobbio dice- integran toda una Teoria del Derecho, ${ }^{29}$ es, en mi opinión, la doctrina que deriva del estudio de las sanciones el criterio que permite definir y, por ende, diferenciar con precisión, los tres grandes órdenes reguladores del comportamiento humano: moral, derecho y convencionalismos sociales. Es indudable que la existencia de todo orden jurídico está necesariamente ligada a la de los aparatos coactivos que aseguran su eficacia, y que ello exige, en forma igualmente necesaria, la institucionalización de las sanciones. Tampoco puede negarse que, dentro de cada orden de esa especie, siempre hay preceptos no sancionados por otros del sistema, y que, cuando el legislador se abstiene de sancionarlos, es porque se halla ante uno de estos dos casos típicos: "1) o se trata de normas para cuya eficacia cuenta - por su reconocida oportunidad, su correspondencia a la conciencia popular o su justicia- con la adhesión espontánea, lo que hace inútil la sanción; o bien, 2) de normas con rango tan alto en la escala jerárquica, que la sanción resulta imposible o, al menos, escasamente eficaz". 30

Un punto débil de la doctrina de Bobbio es la creencia de que lo que condiciona la índole jurídica de una norma no es el hecho de que esté o no sancionada, sino la circunstancia de que tenga su origen en cualquiera de las fuentes reconocidas como legítimas. ${ }^{31}$ Esto equivale, en nuestro sentir, a negar que la coercibilidad sea atributo de la norma jurídica, considerada aisladamente. Reconozco, de acuerdo con el maestro italiano, que una norma puede ser jurídica aun cuando no la sancione otra del sistema, mas no creo que de ello deba concluirse que la coercibilidad es atributo exclusivo del orden jurídico en bloque.

27 Teoria dell'ordinamento giuridico, cap. III.

28 Ibid., cap. IV.

29 Ibid., pág. 3.

30 Ibid., pág. 208.

31 Ibid., cap. I, 3. 
Si la coercibilidad se define como posibilidad de cumplimiento no espontáneo $y$, por ende, de imposición forzada, el mencionado atributo corresponde lo mismo al orden jurídico que a cada una de sus normas. ${ }^{32} \mathrm{El}$ error está, pues, en hacer depender la índole jurídica de aquél y de éstas de la existencia de los preceptos sancionadores, y en la confusión, igualmente errónea, de los conceptos de sanción y coacción. . $^{33}$

Los que polemizan sobre si la coacción es o no de la esencia del derecho suelen olvidar, como observa Henkel, que el término coacción puede emplearse, ya en el sentido de doblegamiento real de la voluntad por ejercicio del acto coactivo, ya en el de posibilidad de dicho acto, o sea, en el de coacción potencial. "Como la efectividad del derecho no consiste en la realización permanente de actos coactivos, el momento de la coacción, en el caso de aquél, normalmente debe entenderse como coacción potencial, esto es, no como hecho, sino como posibilidad jurídica." ${ }^{34}$ Decir - prosigue Henkel- que la coercibilidad (Erzwingbarkeit) es elemento esencial del derecho positivo, significa que éste, en conjunto, no puede prescindir de la impositividad de tipo coactivo. "Pero a ello no se opone que el legislador renuncie, relativamente a normas aisladas, a establecer, en favor de las mismas, la posibilidad de la imposición forzada, o que incluso prohiba semejante forma de imposición. La coercibilidad, como nota esencial y conceptual del orden jurídico no indica, pues, que detrás de todas las normas de éste tenga que existir un aparato coactivo sin lagunas para la imposición de todas las exigencias jurídicas." 35

El problema está en saber si las normas que no se encuentran sancionadas por otras del mismo sistema, tienen también el atributo de coercibilidad que predicamos del todo que las abarca. Entendido el concepto de coercibilidad en la forma en que nosotros lo hacemos, no hay ninguna duda de que aquellas normas poseen el citado atributo. $\mathrm{Y}$ ello por la sencilla razón de que, pese a no estar sancionadas por otros preceptos del sistema, los deberes que imponen pueden ser observados en forma no espontánea, sin que el cumplimiento que carece de espontaneidad pierda por ello su carácter de cumplimiento, en el sentido jurídico del vocablo. Aquí reside, precisamente, una de las diferencias esenciales entre moral y derecho. El cumplimiento no espontáneo - lo mismo que la imposición coercitiva- son compatibles con la observancia de los deberes jurídicos, ya que las normas que los imponen no tienen como fin último el perfeccionamiento del obligado, sino la satisfacción de las facultades del pretensor. ${ }^{36}$ Los deberes morales, por el contrario, son incoercibles por esencia. De hecho puede ocurrir

32 Cfr. E. García Máynez, Introducción al estudio del derecho, cap. II, 11.

33 Ibid., cap. XXI. 155.

${ }^{34}$ Heinrich Henkel, Einführung in die Rechtsphilosophie, C. H. Beck'sche Verlag, München und Berlin, 1964, 1. Teil, 2 Abschnitt, 12, pág. 94.

35 Ibid., pág. 97.

36 Del Vecchio, Filosofía del derecho, tomo I, pág. 424 de la traducción castellana de Luis Recaséns Siches. 
que alguien realice, sin su voluntad, ciertos actos prescritos o prohibidos por una norma. En tal hipótesis, lo que haga carecerá de significación ética. Si el acto es obligatorio, no tendrá el sujeto ningún mérito; si aquél se encuentra vedado, resultará imposible declarar responsable a éste. Expresado en otro giro: si un acto (o una omisión) no pueden interpretarse como manifestaciones espontáneas de la voluntad del obligado, tampoco será posible hablar de observancia de la norma. $\mathrm{Ni}$ siquiera en el caso de que alguien ejecute lo que ésta prescribe, mas no por íntimo convencimiento, sino a fin de evitar, por ejemplo, la realización de una amenaza, habrá cumplimiento auténtico, en la acepción moral de esta voz.

La norma ética no sólo exige obediencia; reclama, además, del sujeto, espontaneidad en su actuación. La voluntad forzada es, ciertamente, voluntad; mas no sería correcto entenderla como indicio de un querer genuinamente libre. Por otra parte, si el orden moral demanda en todo caso que el móvil del comportamiento sea, como decía Kant, el mero respeto a la exigencia normativa, el temor, el interés $o$, en general, cualquiera otro móvil, quedarán totalmente excluidos. Sólo la adhesión libérrima a las prescripciones de aquel orden puede, pues, valer como verdadero acatamiento.

Cosa diversa ocurre con los deberes jurídicos, ya que éstos quedan cumplidos aun cuando el obligado actúe de mal talante. La observancia de tales deberes, lo mismo que la de todos los demás, es voluntaria unas veces e involuntaria otras; pero tanto en el caso en que el sujeto obra con espontaneidad como en el de sujeción voluntaria pero no espontánea o, incluso, en el de imposición forzada, juridicamente cabe hablar de cumplimiento.

Por eso, al sostener que el derecho es coercible o, para hablar con mayor rigor, que los deberes que impone ostentan tal atributo, de ningún modo damos nuestro asentimiento a la doctrina que hace de la coacción un elemento esencial de la regulación jurídica, ni al aserto de que una norma sólo es parte de un sistema si se encuentra sancionada por otra norma de éste. ${ }^{37}$ Insistimos en que coercibilidad sólo significa, dentro de nuestra terminología, posibilidad de cumplimiento no espontáneo y, por tanto, de imposición coercitiva. Mas de aquí no se sigue que un precepto sólo sea jurídico cuando está sancionado por otro de igual naturaleza; cuando es sancionador de otra norma de derecho, o cuando se ordena imponer coactivamente la conducta prescrita.

$\mathrm{Al}$ aseverar que la posibilidad de cumplimiento no espontáneo y, en la mayoría de los casos, de imposición forzada, es necesario atributo de los deberes que dimanan de las normas del derecho, no aludimos, como es obvio, a una simple posibilidad fáctica, es decir, a la de que realmente siempre se pueda constreñir a la observancia de esos deberes. Si entendiéramos así el concepto, más bien habría que sostener que el mencionado atributo no es elemento definitorio del deber jurídico, y ello no sólo porque hay ciertas normas de derecho

37 Sobre este punto, E. García Máynez, Lógica del juicio jurídico, cap. III, 2. 
que no se encuentran sancionadas intramuros del sistema, sino porque a veces no es posible aplicar los preceptos sancionadores.

En lo que respecta a la tesis sobre la unidad del orden jurídico, Bobbio concuerda, substancialmente, con el punto de vista kelseniano. Para el creador de la Teoría Jurídica Pura, la norma fundamental hipotética determina el carácter unitario de cada sistema; pero esa norma tiene que estar referida a un orden eficaz. Cierto que, para Kelsen, la eficacia es conditio sine qua non, mas no conditio per quam de la validez, lo que presupone que el problema de la eficacia, si bien está íntimamente ligado al de la fuerza vinculante, no se confunde con él. ${ }^{38}$

Aun cuando no hay duda de que para llegar a una definición correcta del derecho, en el sentido objetivo del término, hay que partir del estudio. del orden jurídico en bloque, y no de la teoría de las normas, a nosotros nos parece que el horizonte de la investigación debe ampliarse más todavía, de manera que no se parta simplemente del examen del derecho como orden, ni de la noción de orden normativo, sino de una taxología, o teoria general del orden, dentro de la cual el análisis del concepto específico de orden normativo, y del más específico aún de orden jurídico, sean sólo aspectos.

Es verdad que el profesor Bobbio, al plantearse el problema de la definición universal de lo jurídico, hace referencia tanto al derecho como a la moral y a los convencionalismos sociales; pero no elabora una teoría general sobre el concepto cle orden normativo ni sobre el genérico de orden. La circunstancia de que casi todos los autores que dedican una consideración especial a aquel concepto definan el orden jurídico como conjunto de normas ${ }^{39}$ obedece, en mi sentir, a que tal "conjunto", al que sería más correcto dar el nombre de sistema normativo, no es un conjunto, en el sentido técnico de esta voz, ${ }^{40}$ sino una pluralidad de preceptos jurídicos que tienen un fundamento común de validez, y entre los que existen múltiples vínculos de supra y subordinación, condicionados por la forma en que tales preceptos son creados. Se trata, para decirlo de otro modo, de una totalidad unitaria y sistemática, que exhibe un orden propio y tiene el sentido y la finalidad de regular $\mathrm{y}$, por ende, ordenar, la conducta de sus destinatarios, entre los que figuran tanto los facultados y obligados por las normas de comportamiento como los que tienen a su cargo

38 Kelsen, General Theory of Law and State, Part One, I, G, g, pág. 41.

39 Esto puede afirmarse, por ejemplo, de autores como Hans Nawiasky, Allgemeine Rechtslehre, Verlag Benziger \& Co. A. G., Zweite Aufl., Zürich, 1948, 3, pág. 16; Helmut Coing, Grundzüge der Rechtsphilosophie, Walter de Gruyter, Berlin, 1950, I, zweites Kapitel, pág. 18; Hermann Kantorowicz, Der-Begriff des Rechts, Vandenhoeck \& Ruprecht in Göttingen, 1957, Drittes Kapitel, págs. 36 y siguientes; Karl Larenz, Methodenlehre der Rechtswissenschaft, Springer Verlag, Berlin, 1960, Systematischer Teil, I, 1, pág. 145 y siguientes; Bernhard Rehfeldt, Einfïhrung in die Rechtswissenchaft, W. de Gruyter, Berlin, 1962, I, 1, págs. 7 y siguientes; Arthur Kaufmann, Recht und Sittlichkeit, J. C. B. Mohr (Paul Siebeck), Tübingen, 1964.

40 Cfr. "Notas para una teoría del orden", Diónoia, 1965, págs. 3-17. 
el desempeño de funciones públicas, definidas e impuestas por normas de organización.

La reflexión anterior revela que el orden que exhibe el sistema normativo - derivado, según dijimos, de los nexos de supra y subordinación entre los preceptos que lo integran - no debe confundirse con el que éstos instauran entre quienes deben obedecer o están obligados a formular o aplicar los mismos preceptos. Los dos órdenes de que hablamos pueden distinguirse con toda nitidez cuando se advierte que el sistema normativo no es otra cosa que una pluralidad unitaria de pautas o criterios de ordenación de un material ordenable que ya no está constituido por esos criterios o pautas, sino por la conducta de las personas a quienes las normas de derecho facultan u obligan. El orden que dimana de la observancia -o aplicación, en su caso- de los preceptos del sistema no debe, pues, ser identificado con el que -a través de sus múltiples relaciones- ostentan las normas de aquél. Así como no puede decirse que el orden de una biblioteca ${ }^{41}$ esté constituido por el sistema clasificatorio, el de la comunidad jurídicamente organizada tampoco se confunde con el de los preceptos integrantes del sistema normativo. Una biblioteca sólo está ordenada cuando los libros que la forman ocupan todos el sitio que, de acuerdo con el sistema de clasificación, a cada uno corresponde. De igual manera, el orden jurídico concreto o real necesariamente dimana de la sumisión, a los preceptos del sistema, de la conducta de los destinatarios de esos preceptos, ya se trate de los particulares, ya de los encargados de establecer o aplicar las normas vigentes. Si este enfoque es correcto, el término orden jurídico no debe referirse a lo que nosotros llamamos sistema normativo; en realidad conviene al concreto o real que deriva de la eficacia de las normas en vigor. Pero entonces resulta que la teoría tradicional aplica aquel término, más que al orden jurídico en su totalidad, o un elemento de éste, conviene a saber, el que forman los preceptos del sistema.

La nueva perspectiva tiene necesariamente que conducir a un diverso enfoque de numerosas cuestiones básicas de la ciencia y la filosofía jurídicas $y$, especialmente, de la que concierne a los nexos entre validez y eficacia. En efecto: si el orden jurídico concreto o real emana del cumplimiento $-\mathrm{y}$, en su caso, de la aplicación- de sus normas, la eficacia del mismo, más que supuesto o condición de la validez de dichas normas, resulta un elemento de aquél.

Pero antes de desenvolver estas ideas, en consonancia con las Notas para una teoría del orden que publicamos en el número anterior de Diánoia, ${ }^{42}$ creemos conveniente recordar la tesis de un autor para quien la ecuación orden jurídico = sistema normativo no es correcta, ya que las normas del segundo constituyen sólo una parte del primero.

41 Artículo citado, 8, pág. 12.

42 Diánoia, 1965, págs. 3-17. 
2. Orden social $y$ orden juridico, de acuerdo con la doctrina de Theodor Geiger

En su libro Vorstudien zu einer Soziologie des Rechts, ${ }^{43}$ Hermann Luchterhand Verlag, Neuwied am Rhein Berlin, 1964, Th. Geiger parte de la distinción entre orden social y orden jurídico, a fin de elaborar después una teoría en torno de este último.

"El derecho - escribe- es una estructura ordenadora existente dentro de un conglomerado social." 44 Tal aserto no basta, sin embargo, para distinguir al jurídico de otros órdenes sociales. Hay, pues, que encontrar los criterios que pueden conducir al establecimiento de una delimitación rigurosa.

La cuestión consiste en señalar las diferencias entre derecho, en particular, $y$ orden social, en general, como conexiones de orden real, es decir, prescindiendo en absoluto de representaciones de índole metafísica. ${ }^{45}$

A propósito de la segunda de las dos nociones, nuestro autor considera que "el concepto de sociedad humana significa, si lo reducimos a su expresión más simple, que los hombres, en su existir, encuéntranse dirigidos y destinados unos a los otros". ${ }^{46}$ Saber por qué ocurre así, es problema que podrá intranquilizar a los constructores de concepciones del mundo; al sociólogo - y Geiger lo esle basta con percatarse de que así ocurre. ${ }^{47} \mathrm{El}$ hombrc vive en sociedad con sus congéneres, y no podría vivir de otro modo. Cuando hablamos de su "naturaleza social", a lo que en primer término aludimos es al hecho de que la estructura del ser humano encierra, como rasgo de esencia, la relación inter-personal. Psicológicamente, tal hecho se manifiesta en que el individuo, no únicamente en su hacer y omitir, también en su pensar y sus sentimientos, cuenta siempre con sus semejantes. Y ello no sólo "en inclinación simpática", sino a menudo en forma antagonística, "pues la lucha y el conflicto, la enemistad y la guerra son también relaciones sociales". 48 Podemos, pues, sostener que el individuo depende, en su existir total, de su convivencia con sus prójimos o, en otras palabras, que la interdependencia social es su forma de vida.

La existencia en común se desenvuelve como una interminable y enmarañada cadena de acciones y reacciones. Si el hombre ha de vivir en sociedad, tiene que hallarse en condiciones de prever, con seguridad relativa, cómo habrán de conducirse los demás en ciertas situaciones "recurrentes y típicas". ${ }^{49}$ El comporta-

43 Theodor Geiger, Vorstudien zu einer Soziologie des Rechts. (Estudios preliminares para una sociologia del derecho), H. Luchterhand Verlag, Neuwied am Rhein und Berlin, 1964.

44 Ibíd., pág. 43.

45 Ibid., pág. 44.

46 Ibid., pág. 46.

47 Idem.

48 Ibíd., pág. 47.

49 Ibíd., pág. 48. 
miento de los otros, especialmente en conexión conmigo, ha de ser, al menos "dentro de ciertos límites", calculable. "Sólo en este caso puede un sujeto $M_{1}$, dentro de un grupo $\Sigma$, disponer interrelativamente su obrar frente a las reacciones que espera de $M_{2,3} \ldots x ;$ y sólo bajo tal condición puede enlazar su existencia a la de $M_{2,3} \ldots x$." ${ }^{50}$ Geiger da a este fenómeno el nombre de coordinación de los comportamientos, y asevera que en él se refleja el orden del grupo.

De orden social cabe hablar cuando, dentro de un conglomerado social $\Sigma$, hay una firme conexión entre ciertas situaciones típicas $s$ y ciertas correspondientes y típicas formas de conducta $g$. "Si alguien se encuentra en $s$, a tal situación suele seguir el comportamiento $g$. Esta correspondencia entre una situación y un comportamiento se expresa con ayuda de la fórmula $s \rightarrow g$, en que la flecha indica que $g$ sigue a $s . "$ " ${ }^{51}$ orden social no es sino una vasta red de correlaciones que se ajustan al mencionado esquema.

Lo anterior no significa que tales correlaciones tengan siempre - y menos aún en los orígenes- carácter normativo. El modelo o patrón de conducta $s \rightarrow g$ sólo indica, en un principio, determinadas regularidadcs de orden fáctico, que no siempre se interpretan como acatamiento de una norma. Ésta únicamente existe cuando el citado patrón es visto como obligatorio por los miembros del grupo, y la conducta contraria provoca una reacción de la colectividad, o de algunos de sus componentes, contra el infractor. La regla a que se atribuye obligatoriedad o, como dice Geiger, la que ostenta la "marca" o "estigma" $r$, no posee ese carácter en un sentido absoluto; obliga únicamente a determinada clase de personas $(A A)$, a quienes se denomina destinatarios. Puede ocurrir, además, que la conducta impuesta a los obligados favorezca a otra clase de sujetos $(B B)$, que, por ello mismo, reciben el nombre de beneficiarios de la norma. Esta consta, pues, de tres o cuatro elementos, a saber: 1) el núcleo normativo $s \rightarrow g$; 2) el estigma de obligatoriedad $v ; 3$ ) los destinatarios $A A$ y, en ciertos casos, los beneficiarios $B B{ }^{52}$ La envoltura verbal o expresión lingüística de esos elementos traduce en palabras la susodicha relación.

Tanto la regla que se ha formado por costumbre como la expresión proclamativa $^{53}$ de un precepto legal, contienen una expectativa (o exigencia) del grupo, relativamente a los destinatarios de aquéllas. Lo que la envoltura verbal de la norma indica es que la sociedad tiende a lograr, de los sujetos a quienes la exigencia está dirigida, la observancia del patrón de conducta $s \rightarrow g$.

Geiger se pregunta si la llamada obligatoriedad corresponde o no a una realidad. El problema está en que las normas no son necesariamente respetadas, pues no todo $A$ responde a la situación $s$ con la conducta $g$.

50 Geiger, opus cit., pág. 49.

51 Idem.

52 Ibỉd., pág. 62.

53 Ibíd., pág. 65. 
Sostener que a la obligatoriedad de la regla normativa corresponde una conexión real, significa, para el autor de los Vorstudien, que si en vez de ceñirse al patrón de comportamiento $s \rightarrow g$, el sujeto $A$ obra en contra del precepto, su proceder provoca una reacción de "los demás", a los que el propio Geiger designa por medio de la letra $\Omega$.

El hecho es que toda persona que se halle en la situación típica $s$ tiene que elegir entre dos posibilidades: o realiza la conducta $g$, o queda expuesta a la reacción $r$ de $\Omega$. Precisamente esta alternativa constituye "el contenido de realidad" de $v .54 v$ es una "magnitud mensurable", y en cuanto tal podemos considerarla como una función de la relación entre el poder del grupo $(\Sigma)$ sobre los destinatarios $A A$, y el interés que los miembros de la sociedad tienen en el mantenimiento del patrón $s \rightarrow g .55$

A $\Omega$ pertenecen, en principio, todos los miembros $(M M)$ de $\Sigma$, y no sólo los obligados por la norma. Por eso, cuando $A_{c}$ ejecuta un acto violatorio, no puede decirse que todos los $M$ sean sujetos de la reacción $r$. "En este caso $\Omega=M M-A_{c}$." 56

Por tanto, lo más correcto es decir que $\Omega$ son "los otros". ${ }^{57}$

La presión ejercida por la opinión pública $(\Omega)$ de $\Sigma$, asume diversas formas manifestativas. Unas veces dimana del comportamiento regular, más o menos constante, en el sentido del patrón $s \rightarrow g$, de un gran número de miembros del grupo (v. gr., $M_{1}, 2,3 \ldots 1_{100}$ )."Este ejemplo colectivo y cumulativo actúa sugestivamente sobre el sujeto $\left(M_{n}\right)$, que se siente inseguro en el medio social o en la situación típica $s . "{ }^{58} \mathrm{La}$ repetición de la conducta conforme al patrón de comportamiento, impresiona a $M_{n}$, quien, al verse en la situación prevista por la norma, naturalmente tiende a observar la conducta obligatoria. Otras veces, el efecto sugestivo procede de la actitud aprobadora de $\Omega$ relativamente a los actos de obediencia, caso en el cual esa actitud de "los otros" frente a la conducta no-g ${ }^{59}$ exterioriza la representación de que el estigma $v$ conviene a $s \rightarrow g$. Sobre $\mathrm{M}_{\mathrm{n}}$ puede, por último, influir el hecho de que la norma sea verbalmente formulada por el legislador.

Geiger analiza en seguida la presión social que en un caso concreto de $s$ gravita sobre un determinado sujeto $A$. En la medida en que los mecanismos descritos ejercen su influjo, $s \rightarrow g$ llega a ser para $A$ una especie de "segunda naturaleza". 60 " $s \rightarrow g$ resulta para él algo tan comprensible de suyo, que apenas piensa en la posibilidad de no- $g$ ". ${ }^{61}$ Pero cuando cualquiera de los destinatarios

\footnotetext{
54 Geiger, opus cit., pág. 63.

55 Ibíd, pág. 72.

56 Ibid., pág. 73.

57 Idem.

58 Ibid., pág. 78.

59 Ibíd., pág. 79.

60 Ibid., pág. 81 .

61 Idem.
} 
muestra inclinación a la conducta no-g, o la realiza, los mecanismos sociales de control entran en juego.

La reacción del grupo asume diversas modalidades: medidas tendientes a lograr el cumplimiento del precepto o la reparación del daño causado por el acto violatorio, o simples represalias, expiación, castigo, boicot social o exclusión de $\boldsymbol{\Sigma}$. En estadios arcaicos, $r$ puede también consistir en que el violador sea abandonado a la venganza de su víctima. ${ }^{62}$

Mientras el orden social deriva de la costumbre, moral, derecho y usos sociales no se han diferenciado aún, y el mecanismo de control opera espontáneamente en la forma ya descrita: "los otros", es decir, los miembros del grupo, cuidan de que las normas conserven su eficacia. La mirada vigilante de quienes lo rodean, hace que el individuo se abstenga de apartarse de lo que aquéllas ordenan. Si a pesar de todo las vulnera, ello produce una reacción, espontánea e inmediata, de los testigos aculares y, mediatamente, otra, igualmente espontánea, de quienes "por comunicación recibida de esos testigos, por huellas del hecho o en cualquiera otra forma, han tenido conocimiento de la infracción". ${ }^{63} \mathrm{El}$ funcionamiento del mecanismo de control depende, pues, de que el individuo tenga conciencia de que está sujeto a la interesada vigilancia de los demás. $^{64}$

Dentro de un orden jurídico, en cambio, la defensa de las normas y la aplicación de las sanciones no son abandonadas a la "espontánea efectividad" de lo que hagan "los otros", sino que se encomiendan a órganos especiales, lo que trae consigo la institucionalización del orden. "La función pasa de $\Omega$, como tal, a una instancia que actúa en representación de $\Sigma$, y que en lo sucesivo llamaremos $\Delta$. $\Delta$ puede tener a su cargo tanto la función jurisdiccional en sentido propio como la de vigilancia policiaca de $r$." 65

A la aparición de los órganos jurisdiccionales se halla naturalmente ligado el establecimiento de un conjunto de normas procesales. La sanción no sigue ya al entuerto de manera espontánea, y es impuesta en forma reflexiva. Esto significa, como antes se apuntó, que al lado de las normas de comportamiento dirigidas a $M M$, surgen otras relativas a la actuación de $\Delta$.

La entrega de los "controles de orden" a una instancia ad hoc, hace que la red ordenadora se transforme, frente a los particulares, "en un poder exterior". 66 La institucionalización del mecanismo de las sanciones nunca se extiende, sin embargo, a todo el orden social. Representa "una línea de desarrollo", al lado de otra que corre en dirección opuesta. La primera significa, patentemente, una exteriorización", "y a ella corresponde, como acontecimiento

\footnotetext{
62 Geiger, opus cit., pág. 82 .

63 Ibid., pág. 131.

64 Idem.

65 Idem.

${ }^{66}$ Ibid., pág. 132.
} 
polarmente opuesto, una interiorización de las manifestaciones del orden. En la segunda de estas líneas aparece la. moral'".67

Geiger explica cómo, en la etapa de la reacción espontánea $r$ de parte de $\boldsymbol{\Omega}$, el autor del acto vedado desempeña, frente a los otros, un papel pasivo. Éstos deciden, "desde afuera", ejercer presión sobre él. Pero el infractor puede, en otros casos, como miembro de $\Sigma$, intervenir activamente contra nuevos infractores. "Cuando se establece la instancia $\Delta$, este cambio de papeles es suprimido. El mecanismo de control social del orden queda firme y unilateralmente encomendado a manos determinadas." 68

Al extenderse la sociedad portadora del orden a una gran masa de individuos, se constituye un poder central II ( $=\pi 0 \lambda \iota \tau \iota x \nu^{\prime}$ xpá $\tau 0 \varsigma$ ) en que "se condensa" la interdependencia social. Esta -observa Geiger- no se manifiesta ya de modo instintivo en virtud de la pertenencia a un círculo reducido de personas sino, en parte, gracias a la intelección reflexiva de la necesidad vital de subordinarse a un todo social y, en parte tambión, a través de la amenaza de aplicación o de la aplicación efectiva de la coacción organizada. ${ }^{69}$

Al orden social "portador del derecho", Geiger no lo llama "Estado" sino "sociedad jurídica". Ésta abarca a otros agregados sociales, y el derecho, "como red unitaria", está por encima de los órdenes no jurídicos o de la sociedad toda. "De orden jurídico sólo hablamos cuando, dentro de un medio social diferenciado por medio de grupos que existen unos al lado de otros o se limitan recíprocamente, se forma un poder central supraordinado a esos grupos."70 Tal es, para nuestro autor, "la más general y neutra" expresión del concepto "pueblo con suprema organización de poder". ${ }^{71}$ Poco importa que el poder político haya surgido en forma endógena o exógena. Geiger opina que, por regla general, ese poder es la resultante de la subyugación militar de un linaje por otro, y del consiguiente proceso de interpenetración.

Ya se ha dicho que el orden jurídico no es nunca el único dentro de una sociedad diferenciada. La moral y los usos existen paralelamente a él. El sociólogo alemán da a este fenómeno el nombre de pluralismo de las estructuras ordenadoras. ${ }^{72}$

La relación entre Estado y sociedad se presenta, según Geiger, así: "Estado" y "sociedad libre" son estructuras sociales que tienen en común el sustrato personal "población". El orden jurídico está ligado a la forma estatal de vida, mientras que los convencionalismos (Sitte) y la moral lo están a la "sociedad libre" como totalidad, por lo que ciertos grupos y círculos de la misma poseen sus particulares estructuras ordenadoras. La diferenciación entre éstas y el derecho

67 Geiger, opus cit., pág. 294.

${ }^{68}$ Ibid., pág. 133.

69 Ibíd., pág. 149.

70 Ibid., pág. 130.

71 Ibid., pág. 130.

72 Ibíd., pág. 157. 
puede establecerse, primero, en la medida en que el derecho, como tipo de orden, lo es de un conglomerado social específico (el pueblo del Estado); después, en el aspecto morfológico, en cuanto, dentro de la población del Estado (o sociedad jurídica), al lado del derecho existen otros órdenes no jurídicos.

Para determinar cómo se produce la diferenciación de las estructuras ordenadoras, Geiger examina dos hipótesis. Una es que la gran organización social bajo un poder supremo y, con ella, el orden jurídico, han tenido su origen, en forma endógena, en una preexistente sociedad de igual sustrato, no centralizada. Esta sociedad se halla, en un principio, regida por costumbres de índole moral o convencional. Pero, al constituirse el poder central, paralelamente se produce una "jurificación" ("Jurifikation") de algunas partes de la estructura primitiva, mientras que otras siguen sujetas a la regulación espontánea de la moral o los usos. En el segundo supuesto, es decir, el de surgimiento exógeno del poder político, la gran sociedad dirigida por éste aparece cuando, en virtud de la conquista militar, dos o más conglomerados sociales hasta entonces independientes quedan unidos bajo la dominación de uno de ellos. ${ }^{73}$

Los rasgos característicos o distintivos del orden jurídico son, pues, éstos: 1) existencia de un gran conglomerado social interiormente diferenciado y estructurado; 2) dirigido por un poder central; 3) que ejerce el monopolio de la actividad sancionadora, ya en lo que respecta a la aplicación, ya en lo que atañe a la ejecución de las sanciones; 4) el ejercicio de ese monopolio se encomienda a una instancia $\Delta$, que puede coincidir con el poder central o estar formada por órganos del mismo; 5) tal ejercicio se encuentra normativamente regulado, en parte por el establecimiento de un procedimiento formal para la aplicación de la reacción contra el entuerto, en parte 6) por regulación de las sanciones desde el punto de vista de su relación con la gravedad de los actos violatorios (principio de proporcionalidad).$^{74}$

En la medida en que estas notas coinciden en un orden social, concluye Geiger, podemos darle el calificativo de jurídico. Si alguna de ellas falta, sólo podrá hablarse de "derecho imperfecto". 75

Si cotejamos las doctrinas, arriba expuestas, de Norberto Bobbio y Theodor Geiger, ante todo descubrimos que ambos juzgan que una definición correcta del derecho sólo puede obtenerse si se concibe a éste como orden social sui-generis. Ello explica que tanto el jurista italiano como el sociólogo alemán coloquen en el primer plano del análisis la noción de orden juridico y no, como tradicionalmente se ha hecho, la de norma jurídica. Bobbio y Geiger coinciden, además, pese a la diversidad de los métodos que emplean, en que para distinguir el derecho de otros órdenes reguladores del comportamiento humano hay que atender a la naturaleza de las sanciones $y$, especialmente, a la forma de su estableci-

73 Geiger, opus cit., pág. 158.

74 Ibíd., pág. 168.

75 Idem. . 
miento y aplicación. Por ello declaran que la característica diferenciadora de aquél, frente a esos otros órdenes, consiste en que sus sanciones son de índole externa y se encuentran institucionalizadas. ${ }^{76}$

Pese a que los dos autores dirigen primordialmente su atención al estudio del derecho como orden, entre las nociones que uno y otro tienen del jurídico existe una diferencia esencial, que en buena parte obedece al enfoque normativista de Bobbio y sociológico de Geiger: para el primero, orden jurídico es un conjunto de normas, sistemáticamente estructurado; para el segundo, el sistema normativo es sólo un elemento del orden social concreto que llamamos derecho."

A fin de precisar mejor la apuntada discrepancia, permítasenos recordar la definición propuesta por Geiger: "Derecho es un mecanismo ordenador monopolizado por un poder central." 78 Esta definición, que establece un indisoluble enlace entre las nociones de orden jurídico y Estado, engendra una serie de dificultades de las que Geiger tiene conciencia, puesto que se enfrenta a ellas, pero sin lograr superarlas. La mayor, sin duda alguna, deriva del siguiente interrogante: ¿ es el llamado "internacional" realmente derecho, de acuerdo con la definición anteriormente recordada?

Examinemos la respuesta del propio Geiger. Aun cuando pueda discutirse hasta qué punto las normas del "derecho internacional" sean obligatorias, es, empero, evidente, que "pretenden" ser "jurídicas", yã que presentan "Ios síntomas reconocibles del proceso histórico que tiende a superponer, a la pluralidad de los Estados, una estructura supraestatal unitaria. El concepto del derecho no abandona, en la expresión derecho internacional, su (per definitionem) pertenencia al concepto Estado. Se habla de derecho internacional precisamente porque en la creación de éste el Estado se proyecta sobre los Estados históricos como pensamiento de un orden supranacional, o Estado mundial". La formación del derecho y la del Estado corren paralelamente, pero, "en este caso, la del primero se anticipa a la del segundo".79

Sin negar que las precedentes afirmaciones sean correctas, a nosotros nos parece que una vez definido el derecho como "mecanismo ordenador monopolizado por un poder central", no es posible sostener que el "internacional" es verdadero derecho, ya que aún no existe un poder por encima de los Estados. El aserto de que el sentido de la evolución histórica revela la tendencia a superponer a éstos "una estructura supraestatal unitaria", no resuelve, pese a su verdad, el problema que estamos discutiendo, pues lo que en rigor se desprende de las palabras de Geiger es que, cuando esa estructura supraestatal unitaria exista, el "derecho internacional" caerá bajo la definición que el sociólogo alemán ofrece en la página 133 de sus Vorstudien. Pero aseverar que el internacional puede, en

76 Bobbio, Teoria della norma giuridica, 42, pág. 197; Geiger, opus cit., pág. 131.

77 Geiger, opus cit., pág. 57.

78 Ibíd., pág. 133.

79 Ibid., pág. 221. 
lo futuro, convertirse en derecho, equivale a admitir que - al menos de acuerdo con tal definición- no lo es todavía.

Nuestro autor argumenta que "una organización central embrionaria de los Estados existe ya", si bien no cabe negar "que carece de instrumentos apreciables de poder frente a los Estados más fuertes". ${ }^{80}$ Se han creado igualmente iristancias jurisdiccionales, pero no hay duda de que "por ahora" no están en condiciones de pronunciarse en contra de una gran potencia, ni de que, "si lo hicieran, carecerían de medios para ejecutar sus fallos".81 Por eso, en el orden internacional la "seguridad de orientación" es bastante mayor que "la de realización".82

En las relaciones reciprocas de los Estados pequeños, las normas internacionales reconocidas son en gran medida eficaces. Resultan igualmente eficaces las de esos Estados con las grandes potencias. $Y$ en lo que a estas últimas respecta, ostentan también "cierto grado de obligatoriedad", que suele manifestarse de tres maneras: "1) Una vez reconocida la norma, no se la viola sin necesidad en perjuicio del débil"; 2) las grandes potencias vigilan en forma recíproca su comportamiento frente a los países menores; 3) existe, por último, un efecto formal, nada despreciable, de las normas del derecho internacional "como germen de futuras realidades", pues "nunca se tiene el descaro de admitir que uno se sirve, sin escrúpulos, de la superioridad que otorga la fuerza". ${ }^{83}$ Consecuentemente, "si la norma es vulnerada in re, se juzga necesario reconocerla pro forma". ${ }^{84}$ Quien no desee sostener, de manera categórica, que el "internacional" es "derecho vigente", que acepte, al menos, que existe como "derecho imperfecto" o, si prefiere la expresión, "como derecho in statu nascendi". 85

Este efugio tampoco es feliz, porque si el llamado "imperfecto" es derecho, pese a su imperfección, habría que ampliar de tal suerte la definición de Geiger, que bajo ella pudieran caer tanto el perfecto como el imperfecto; y si, por imperfecto, el internacional no es derecho, indudablemente queda fuera de lo definido.

Los escollos que Geiger no logra sortear son, en cambio, hábilmente esquivados por el jurista italiano. Bobbio tiene clara conciencia de que la definición del derecho como orden normativo con sanciones externas e institucionalizadas no implica que sólo pueda ser jurídico el del Estado. El derecho de gentes "nació con la reglamentación de la guerra, es decir, ligado al conocimiento, por parte de los miembros de la comunidad estatal, del carácter sancionador de la guerra y, consecuentemente, de la necesidad de fijarle límites por medio de re-

80 Geiger, opus cit., pág. 224.

81 Ibid., pág. 225.

82 Ibíd., pág. 224.

83 Ibíd., pág. 224.

84 Ibid., pág. 225.

85 Ibíd., pág. 225. 
glas aceptadas de común acuerdo". ${ }^{86}$ Hablar del nacimiento de aquel derecho y de la institucionalización de la guerra como sanción es, pues, lo mismo. "Que el internacional tenga sus propias sanciones y establezca el modo y medida de su ejercicio es tesis admitida por algunos internacionalistas. La violación de esas normas por un Estado constituye un acto ilícito." ${ }^{87}$ ¿Es que los de esta especie no producen ninguna consecuencia? De que la producen no hay duda, pues tanto las represalias como, en casos extremos, el recurso bélico, son, si se ajustan a las mencionadas normas, la única posible y legítima respuesta a los actos violatorios dentro de la sociedad de los Estados. Tal respuesta sólo puede interpretarse en una de estas dos formas: o como reacción libre, en el sentido de no sujeta a restricciones de ninguna especie, o como respuesta regulada por preceptos de derecho. La regulación de las represalias y la guerra hace, pues, del internacional un orden jurídico, ya que se trata de un sistema de normas cuyas sanciones, de índole externa, se encuentran normativamente reguladas. ${ }^{88}$

Si alguna diferencia existe entre los órdenes jurídicos nacional e internacional, añade Bobbio, tal diferencia reside no en que el último carezca de sanciones, sino en la forma de aplicación de éstas. "Si damos el nombre de tutela al complicado proceso de la sanción organizada, cabe distinguir entre un proceso de autotutela, que aparece cuando el titular del derecho de ejercitar la sanción cs el mismo del derecho violado, y un proceso de heterotutela, que tiene lugar cuando los titulares de esos dercchos son personas distintas." sq

Si un Estado ejerce, por ejemplo, represalias contra otro, para responder a la violación de determinadas normas de derecho internacional, la conducta del primero constituye, indudablemente, un acto de autotutela. La diferencia entre el orden internacional y el interno no reside en la ausencia o presencia de las sanciones, sino en el hecho de que, en un caso, la organización de éstas se basa en el principio de la autotutela y, en el otro, en el de la heterotutela. Y el hecho de que la autotutela corresponda a una sociedad menos perfecta que la que descansa en el otro principio, no es una diferencia esencial, sino de grado, y esa diferencia todo el mundo la reconoce. ${ }^{90}$

Las dificultades de la postura de Geiger derivan, pues, de su definición del derecho o, para expresarlo de modo más preciso, de la creencia de que el jurídico es, en todo caso, un mecanismo ordenador monopolizado por un poder central. La tesis de que lo que distingue al derecho de otros órdenes es la índole externa e institucional de las sanciones jurídicas puede perfectamente mantenerse sin necesidad de ligar la existencia de aquél a la de un poder central supremo o, en otras palabras, sin establecer una ecuación entre orden jurídico y orden político. Para que pueda hablarse de institucionalización de las sanciones

86 Bobbio, Teoria della norma giuridica, pág. 215 .

87 Idem.

\& Idem.

89 Ibid., pág. 216.

90 Ibid., pág. 217. 
basta, en efecto, que la respuesta a los actos violatorios se encuentre regulada por las normas del orden cuya eficacia se pretende asegurar, es decir, en el caso que analizamos, por las del derecho de gentes. Que la sanción organizada no es, en todo caso, la estatal, y que hay "aparatos coactivos" no estatales, fue ya sostenido hace cuatro décadas por Max Weber, en su famosa obra Economía y' Sociedad.91 Weber no acepta que "sólo se hable de 'derecho' allí donde, en virtud de la garantía del poder político, existe la posibilidad de la coacción jurídica"... "De 'orden jurídico' queremos más bien hablar cuando hay la posibilidad de aplicación de cualquier medio coactivo, físico o psíquico, por un aparato coaccionador, es decir, por una o varias personas dispuestas a proceder así, en el caso de que se produzca el hecho jurídico correspondiente o, en otras palabras, cuando existe una forma específica de socialización destinada a ejercer la 'coacción jurídica'." 92

Coincidimos totalmente con Geiger en el aserto de que el orden jurídico no debe identificarse cỏn el sistema normativo, pues dentro del primero, que es el único concreto o real, el segundo es sólo un elemento. Por ello hemos afirmado que una cosa es el criterio ordenador y otra diversa el orden que deriva de la aplicación de tal criterio (o de las reglas que lo constituyen o de él derivan) al material ordenable, es decir (en el caso del derecho), a los destinatarios de esas reglas.

No podemos aceptar, en cambio, que la obligatoriedad o validez deba definirse como probabilidad de que una persona que se halla en cierta situación típica, o bien observe determinado comportamiento, o quede expuesta a que los órganos jurisdiccionales del Estado le impongan tal o cual sanción.

Como el propio Geiger lo proclama, su doctrina sobre la validez responde al propósito de explicar este concepto sin recurrir a representaciones metafísicas o a consideraciones de carácter psicológico.

El problema consiste, para él, en demostrar que a la idea de norma corresponde "una conexión empírica real".

La cuestión puede precisarse así: ¿es que los destinatarios tienen la representación de que la norma es obligatoria y, consecuentemente, la cumplen, o el patrón de comportamiento $s \rightarrow g$ corresponde a alguna realidad, independientemente de las representaciones de $A A{ }^{93}$

Geiger no niega que los destinatarios de un precepto jurídico puedan creer que éste es obligatorio para ellos; pero tal creencia no constituye, en modo alguno, el fundamento de la fuerza vinculante o, como a Geiger le place decir, del estigma $v$ atribuido al precepto. Si dicho estigma o marca refleja una realidad,

91 Max Weber, Economía y sociedad, II, Tipos de Comunidad y Sociedad, Trad. Roura Parella, Fondo de Cultura Económica, México, 1944, cap. VI.

92 Max Weber, Rechtssoziologie. Hermann Luchterhand Verlag, Neuwied, 1960, 1, pág. 59.

93 Geiger, opus cit., págs. 86 y siguientes. 
ésta sólo puede consistir en la probabilidad que la norma tiene "de producir efectos".94

Claro que el patrón de conducta $s \rightarrow g$ no es necesariamente obedecido. La norma no dice que en la situación $s$ todos los destinatarios observen la conducta $g$, sino que "están obligados a observarla". Esto equivale a declarar que pueden, de hecho, infringirla. ¿Diremos entonces que sólo es válida cuando la acatan, y que carece de validez cuando la violan? Indudablemente que no. La norma es obligatoria en todos los casos que integran su ámbito de aplicación o, expresado en otros términos: su obligatoriedad no queda destruida por los actos de incumplimiento. 95

Hemos dicho que, para Geiger, la eficacia de $v$ se determina disyuntivamente, ya que consiste $o$ en la realización del núcleo normativo $s \rightarrow g$, $o$ en la reacción social $r$, como consecuencia de la conducta violatoria. " $v$, en cambio, el concepto de obligatoriedad, no está disyuntiva, sino unitariamente determinado. No es una cosa o la otra; su contenido consiste en el 'o una cosa o la otra', esto es, en la alternativa misma, frente a la cual $A A$ se encuentran colocados". ${ }^{96}$

Conviene advertir, ante todo, que la alternativa en que Geiger pretende fundar la obligatoriedad de las normas del derecho no puede considerarse como una disyunción no exclusiva, en el sentido lógico del término. Si tratásemos de presentarla como tal, resultaría falsa, pues, como el mismo autor lo reconoce, a veces ocurre que ninguno de sus términos se realiza.

No es posible concluir, sin embargo, que cuando la norma no es cumplida ni la sanción aplicada, el estigma $v$ desaparece. "Una norma obligatoria en la generalidad de los casos y no obligatoria de vez en cuando, sería un monstruo conceptual." 97 Para determinar rigurosamente el "contenido de realidad" de $v$ es necesaria una modificación. Cuando un sujeto viola una norma jurídica, queda expuesto al peligro de sufrir la reacción $r$. Su riesgo corresponde a la probabilidad de que la norma resulte efectiva. Esta probabilidad puede expresarse como porcentaje o "cuota" de la totalidad de los casos de $s$. "Si a los de eficacia los designamos por medio de la letra $e$ y a los de ineficacia por medio de la letra $i$, $e$ e $i$ resultarán magnitudes complementarias en relación con $s$. $\mathrm{O}$ sea: $s=e+i$." 98 La obligatoriedad es, pues, relativa, como lo expresa la fórmula $v=e / s$, en que $e$ simboliza todos los casos de cumplimiento de lo prescrito o de aplicación de $r$. Esto - advierte Geiger- no debe interpretarse en el sentido de que la norma sólo sea obligatoria en los casos de $e$ y no en los de $i$. Es obligatoria en todos, pero en cada uno de ellos su intensidad queda expresada por la relación ${ }^{e} / s^{9}{ }^{99} \mathrm{La}$ obligatoriedad tiene, pues, "la propiedad de un hecho que puede comprobarse

94 Geiger, opus cit., pág. 65.

95 Ibid., pág. 69.

\% Ibíd., pág. 70.

97 Ibid, pág. 70.

98 Ibíd., pág. 71.

99 Idem. 
en el mundo real. Esta propiedad reside en la correlación entre $s$, por una parte, y la alternativa ' $g$ o $r$ ', por la otra". ${ }^{100}$ Geiger insiste en que tal relación es numéricamente expresable: "En lo que respecta al pasado, sobre la base de la estadística; en lo que atañe al futuro, como 'cuota de probabilidad'." 101

Nosotros pensamos que lo único que esta teoría explica y, sobre todo, lo único que puede "medirse" o "calcularse", es la eficacia de las normas, no su validez u obligatoriedad. Podemos fácilmente establecer, si disponemos de estadísticas fidedignas, en cuántos casos las del derecho son acatadas por los destinatarios, y en cuántos - a falta de cumplimiento voluntario- tienen que imponerlas los aparatos coactivos. Igualmente es posible medir la ineficacia - mayor o menor- de un precepto, y calcular, en relación con lo porvenir, la probabilidad de que sea o no cumplido o aplicado. Pero todo esto presupone la existencia de la norma cuya eficacia se investiga, y este último atributo (el de eficacia) es el único susceptible de medida.

Declarar que el fundamento del estigma $v$ no reside en las representaciones de los destinatarios sobre la fuerza vinculante del precepto, sino en la alternativa: "cumplimiento o sanción", es psicológicamente falso, pues cuando un sujeto $A$ está convencido de que un patrón de conducta del tipo $s \rightarrow g$ expresa un deber ser y no, simplemente, una regularidad nacida del hábito, la representación de ese deber no deriva de que $A$ considere probable que los destinatarios (él entre ellos) cumplan o, de no cumplir, queden expuestos a una sanción, sino del nexo que ese sujeto establece entre la norma y el valor que atribuye a la realización de la conducta $g$. Expresado en otro giro: si alguien se siente obligado por una regla de conducta y concede a ésta validez normativa, tal sentimiento nunca procede de un cálculo sobre la probable eficacia de aquélla. Atribuir validez a un patrón de comportamiento es, por el contrario, estar persuadido de que, independientemente de que los destinatarios quieran o no sujetarse a él, e independientemente también de que lo respeten o lo violen, y de que haya una instancia cuya tarea consista en imponerlo, la conducta prescrita es obligatoria en todo caso, porque la norma que la ordena tiene su fundamento en un valor objetivo. ${ }^{102}$ Si he causado injustamente un daño, y me siento obligado a repararlo, la validez que atribuyo a la correspondiente norma está condicionada por mi convicción de que la justicia debe ser, y no por el hecho de que estadísticamente pueda demostrar, por ejemplo, que en $87 \%$ de los casos en que un sujeto injustamente daña a otro, el culpable repara el daño o, si se niega a repararlo, la víctima puede obtener de los órganos jurisdiccionales que constriñan al primero a pagar una indemnización. Además, la aplicación de procedimientos coactivos por aque-

100 Geiger, opus cit., pág. 71.

101 Idem.

102 Cfr. E. García Máynez, "Validez formal y validez material en sentido jurídicopositivo, y validez objetiva o intrínseca en sentido axiológico", en Symposium sobre derecho natural y axiología, XIII Congreso Internacional de Filosofía. Ed. Centro de Estudios Filosóficos, Universidad Nacional Autónoma de México, 1963, págs. 83-97. 
llos órganos es, igualmente, objeto de un deber jurídico, por lo que la obligatoriedad del precepto que lo impone tiene también que explicarse (y Geiger lo hace así) como probabilidad de que el órgano jurisdiccional sancione en determinadas circunstancias al violador de la norma primaria $o$, si no lo sanciona, otro órgano de mayor jerarquía sancione al inferior. ${ }^{103}$ Pero es obvio que si éste fuese el fundamento de la obligatoriedad de las normas que regulan los actos de los órganos coactivos, la de las normas concernientes a los de mayor rango, sobre los que no existen otros facultados para imponerles sanciones por inobservancia de sus deberes, no podría explicarse del mismo modo.

Geiger argumenta que si bien la conducta de los destinatarios de una norma se halla motivada por ciertas representaciones de esos sujetos, que los inducen ya al cumplimiento, ya a la violación, lo único que debe interesar al sociólogo es la efectividad de la regla normativa. Estamos de acuerdo en que, desde un punto de vista sociológico estricto, el orden jurídico real de un conglomerado $\Sigma$ es el que deriva de la eficacia del sistema normativo de ese orden, es decir, de los actos de cumplimiento o aplicación de los preceptos integrantes de tal sistema. Lo que parece discutible, en cambio, es que no se conceda importancia a los motivos determinantes de la conducta de los destinatarios de dichos preceptos.

¿Es que estos motivos (representaciones de la fantasía los llama Geiger) no son también reales? ¿ Por qué sólo ha de tener valor científico el conocimiento de la eficacia de las normas jurídicas, y no el de los resortes que la condicionan? Y, sobre todo: ¿cómo entender los actos de sometimiento, si la obligatoriedad de las normas se hace consistir en la probabilidad de ciertas conductas que pierden todo sentido si las desligamos de las representaciones de los sujetos actuantes?

La necesidad de atender a los aspectos internos del obrar que concuerda con los preceptos jurídicos se impone al propio Geiger, pese a su afirmación categórica de que "las representaciones de la fantasía" de los destinatarios no pueden ser objeto de un conocimiento científico. ${ }^{104} \mathrm{La}$ mejor prueba de este aserto la encontramos, precisamente, en los argumentos que invoca al sostener que el llamado "internacional" sí es derecho, pese a su "imperfección". Recuérdese cómo, al abordar el tema, habla de las normas internacionales "reconocidas" por los Estados, y de las razones de orden psicológico que dan a tales normas cierto grado de eficacia. ${ }^{105}$ Su doctrina sobre las "dimensiones de la seguridad" y, especialmente, la distinción entre seguridad de orientación (o "certeza del orden") y seguridad de realización (o "confianza en el orden") no pueden, por otra parte, entenderse recurriendo al concepto de "conexión real" sino, exclusivamente, en función de determinadas "representaciones" de los miembros de la comunidad jurídica.

103 Geiger, opus cit., pág. 144.

104 Ibidd., pág. 206.

105 Ibíd., pág. 224. 
Aun cuando - apartándose en este punto de la tesis de la Escuela de UpsalaGeiger afirme que el sociólogo del derecho no debe llegar al extremo de prescindir en sus desarrollos del concepto de norma, los esfuerzos que realiza para desligarlo de cualquier conexión con las nociones de deber y valor resultan, a nuestro juicio, frustráneos. La "validez" de las normas de conducta no puede reducirse a simples "conexiones de orden real", por la sencilla razón de que el objeto que tal concepto designa no pertenece al orden del ser. Resulta ilógico, por tanto, mantener el término y negar la esencia de aquello a que se refiere. $Y$ decir, como nuestro autor lo hace, que "en cuanto el concepto de norma corresponde a una conexión de la realidad carece de significación normativa", ${ }^{106}$ es una contradicción y no otra cosa.

Las objeciones que hemos dirigido a su doctrina demuestran que, en vez de explicar la "obligatoriedad", lo único que Geiger consigue es definir la "eficacia" de las normas de que estamos tratando. Es patente, y en este punto coincidimos con él, que el último de tales atributos está necesariamente ligado a todo orden jurídico concreto. Pues decir que cualquiera de esta especie existe como tal, significa, precisamente, que su sistema normativo efectivamente regula la conducta de los destinatarios. Pero una cosa es la éfectividad de las normas integrantes de ese sistema y otra muy distinta su validez u obligatoriedad. Incluso quienes aseveran, como Kelsen, que el primero de los mencionados atributos es conditio sine qua non del segundo, se apresuran a añadir que la eficacia no es nunca conditio per quam de la obligatoriedad del sistema.

¿Cómo debe, pues, explanarse la relación entre aquellos atributos? Si referimos la pregunta al orden jurídico, y por tal entendemos no las normas vigentes en su conjunto, sino el orden concreto o real dimanante de la sujeción a tales normas, por parte de los sujetos a quienes éstas se dirigen (ya se trate de los particulares que deben obedecerlas, ya de los órganos encargados de aplicarlas), resulta obvio que la eficacia del sistema normativo es un elemento del orden jurídico concreto, en la medida en que, relativamente a éste, concebido como fin inmediato, aquélla constituye el medio o instrumento de realización.

Retomando el ejemplo de que anteriormente nos servimos, podemos sostener que así como el orden de una biblioteca está 'condicionado por la aplicación del criterio ordenador (o sistema clasificatorio) al material ordenable, y tal aplicación es el medio que permite realizar la finalidad del sujeto ordinante, del mismo modo, el orden jurídico real de una sociedad no,es el sistema normativo de ésta, sino el resultado de la sujeción de los destinatarios a las normas que integran dicho sistema. Sólo cuando tales normas son cumplidas o aplicadas, el orden jurídico se convierte en realidad, y los actos de cumplimiento o aplicación asumen el carácter de medios de realización de las finalidades del ordinante (la sociedad juridicamente organizada).

106 Geiger, opus cit., pág. 66. 
El valor explicativo de nuestro parangón no se agota con lo anteriormente dicho. En el caso de una biblioteca, el orden de la misma depende de que los libros que la forman ocupen el lugar que, de acuerdo con el criterio ordenador, a cada uno conviene. Si imaginamos que, en un cierto momento, todos los volúmenes se hallan en el sitio que el sistema de clasificación les señala, podremos afirmar que, al menos relativamente a tal momento, el orden de la biblioteca es perfecto. Pero esta perfección desaparece si alguno o algunos de los libros no están donde les corresponde, porque el bibliotecario los ha clasificado mal o no ha sabido colocarlos en el lugar debido. Los órdenes de carácter cósico son, pues, perfectibles, y lo propio cabe decir de los de naturaleza normativa. El que a travês de los últimos se pretende instituir está condicionado siempre por la mayor o menor eficacia de sus normas, o, lo que es igual, por el grado y medida en que los destinatarios ajusten a ellas su conducta. Pero el sometimiento, libre o impuesto, a un conjunto de reglas, si bien condiciona la eficacia de estas últimas, nada indica acerca de la bondad o valor de su contenido. Análogamente, el orden real de una biblioteca o de un museo deriva de la aplicación del criterio ordenador al material ordenable (libros en un caso, cuadros en el otro); pero el hecho de que los libros o los cuadros ocupen el sitio que de acuerdo con el sistema de clasificación les corresponde, no es garantía de la bondad de ese sistema. Si ordeno los cuadros de un museo de acuerdo con su precio, o los libros de una biblioteca atendiendo a su tamaño o al color de sus tejuelos, y tanto aquéllos como éstos quedan sometidos a esas reglas de ordenación, podré decir que he realizado mi propósito, mas no que el sistema de clasificación sea bueno o malo. La eficacia de un orden no es, pues, índice de su valor. Del mismo modo, la de una regla de conducta, o todo un conjunto de reglas, tampoco permite afirmar que éstas sean intrínsecamente valiosas. Para atribuirles valor intrínseco tengo que atender, no a la eficacia del orden, sino a las finalidades que la aplicación de las susodichas reglas permite realizar. ${ }^{107}$ En el caso concreto de un orden jurídico puede perfectamente ocurrir que la eficacia del sistema normativo, más que resultado de actos de cumplimiento, sea consecuencia de actos de imposición. $Y$ entonces es muy probable que los destinatarios, más que ligados por el derecho, se consideren sometidos al poder. Por ello hemos escrito en otra parte ${ }^{108}$. que la seguridad jurídica no puede simplemente consistir en la imposición de los preceptos en vigor, porque la única seguridad genuina es la fincada en la justicia. Si la realización (a través de actos de imposición o de obediencia) de un sistema legal justo es un valor positivo, la de un sistema legal injusto es un valor negativo. Aun cuando no se acepte que los valores que el legislador pretende realizar sean objetivos, o se diga que no es posible probar que lo sean, resulta evidente que los destinatarios

107 Cfr. E. García Máynez, "Notas para una teoría del orden" en Diánoia, 1965, pág. 8 y siguientes.

108 E. García Máynez, La definición del derecho, Universidad Veracruzana, 2a. ed. Xalap̣a, 1960, cap. VII, v, págs. 200 y siguientes. 
de las normas no pueden dejar de plantearse el problema de la bondad o justicia intrínsecas de tales preceptos, ${ }^{109} \mathrm{y}$ que sus juicios acerca del contenido de esas prescripciones o, en general, de las oriundas de las fuentes formales, determinan en buena medida los actos de obediencia o desacato y, por ende, la mayor o menor eficacia de la regulación normativa. Si esto es así, el estudio del orden jurídico concreto o real de una sociedad no deberá limitarse al examen y sistematización de los preceptos que el poder público considere obligatorios, ni -en actitud sociológica - a la comprobación de su eficacia; tendrá también, para ser exhaustivo y descubrir el espíritu del sistema, que tomar en cuenta las finalidades perseguidas por los creadores de esas normas $y$, por tanto, los valores que a través de estas últimas pretenden aquéllos realizar. ${ }^{10}$

Eduardo García Máynez

109 Véase el trabajo citado en la nota 102.

100 La segunda parte de este artículo será publicada en el próximo número de Diánoia. 